Pacific Journal of Mathematics

BOUNDS OF ANALYTIC FUNCTIONS OF TWO COMPLEx
VARIABLES IN DOMAINS WITH THE BERGMAN-SHILOV

J. ŚLADKOWSK 


\title{
BOUNDS OF ANALYTIC FUNCTIONS OF TWO COMPLEX VARIABLES IN DOMAINS WITH THE BERGMAN-SHILOV BOUNDARY
}

\author{
J. ŚladKowsKa
}

Introduction. From the function-theoretic point of view, the threedimensional boundary of a domain (in the space of two complex variables) does not play a role analogous to the boundary curve in the theory of one variable. In order to be able to use methods similar to those in one variable, Bergman introduces analytic polyhedra, i.e., domains bounded by finitely many segments of analytic hypersurfaces. ${ }^{1}$ On the threedimensional boundary of an analytic polyhedron lies a two-dimensional manifold which, from the function-theoretic point of view, plays a role similar to that of the boundary curve. In studying the value distribution of holomorphic and meromorphic functions in an analytic polyhedron, we can distinguish with Bergman two types of problems:

(1) derivation of bounds for a function in terms of values on the (two-dimensional) distinguished boundary (the so-called Bergman-Šilov boundary),

(2) studies of the relations between the value distribution on the complementary part of the boundary and in the interior of the domain. While studies of problems of type (1) proceed along the lines similar to those in the case of one variable (through repeated use of the Cauchy and Poisson-Jensen formula, etc.), the investigation of problems of type (2) has a different character. Bergman and Charzyński considered the case of functions $f\left(z_{1}, z_{2}\right)$ which belong to a normal family in every lamina. For instance, they assume $f\left(z_{1}, z_{2}\right)$ to be a Schlicht function in every lamina. In this case it is possible to obtain bounds for $|f|$ in terms of its maximum along a one-dimensional boundary manifold. In the present paper, the investigation of problems of type (2) is continued, and we assume that the function $f$ in every lamina is mean multivalent of order $p$ (see $\S 1$ for details). The order $p=p(\lambda)$ is a function of the parameter $\lambda^{2} ; p(\lambda)$ is square-integrable.

Let $\mathbb{S}^{2}$ be a segment of an analytic surface $\mathbb{S}_{0}^{2}$ which intersects the polyhedron. We obtain bounds for $\left|f\left(z_{1}, z_{2}\right)\right|,\left(z_{1}, z_{2}\right) \in \$^{2}$, in terms of

(a) the minimum and the maximum of $|f|$ on the one-dimensional manifold mentioned before,

(b) a quantity connected with $p(\lambda)$,

Received May 16, 1962. This work was done under NSF Grant 10375.

${ }^{1}$ An analytic hypersurface is a one-parameter family of analytic surfaces called a laminas.

2 The laminas of a segment of an analytic hypersurface depend on a parameter $\lambda$. 
(c) certain constants which depend only upon the domain and the surface $\mathfrak{G}_{0}^{2}$.

o. Definitions and notations. We shall consider an arbitrary bounded domain $\mathfrak{B}$ lying in the space of two complex variables $z_{1}, z_{2}, z_{k}=$ $x_{k}+i y_{k}, k=1,2$. We assume that the boundary $\mathfrak{b}^{3}$ of this domain consists of finitely many segments

$$
\mathrm{e}_{k}^{3}, \quad k=1, \cdots, n,
$$

of analytic hypersurfaces. Every such segment is given by a parametric representation of the form

$$
z_{1}=h_{1 k}\left(Z_{k}, \lambda_{k}\right), \quad z_{2}=h_{2 k}\left(Z_{k}, \lambda_{k}\right),
$$

where $h_{1 k}\left(Z_{k}, \lambda_{k}\right)$ and $h_{2 k}\left(Z_{k}, \lambda_{k}\right)$ are continuously differentiable functions of $Z_{k}, \lambda_{k}$ in the set $\left\{\left(Z_{k}, \lambda_{k}\right):\left|Z_{k}\right| \leqq 1,0 \leqq \lambda_{k} \leqq 2 \pi\right\}$. For a fixed $k$ and $\lambda_{k}$ the corresponding set of points $(0.2)$ will be called a lamina of $\mathfrak{e}_{k}^{3}$ and designated $\mathfrak{\Im}_{k}^{2}\left(\lambda_{k}\right)$. We assume that

$$
\Im_{k}^{2}\left(\lambda_{k}^{\prime}\right) \cap \Im_{k}^{2}\left(\lambda_{k}^{\prime \prime}\right)=0 \text { if } \lambda_{k}^{\prime} \neq \lambda_{k}^{\prime \prime},
$$

and that for fixed $\lambda_{k}$

$$
\left(h_{1 k}\left(Z_{k}^{\prime}, \lambda_{k}\right), h_{2 k}\left(Z_{k}^{\prime}, \lambda_{k}\right)\right) \neq\left(h_{1 k}\left(Z_{k}^{\prime \prime}, \lambda_{k}\right), h_{2 k}\left(Z_{k}^{\prime \prime} \lambda_{k}\right)\right) .
$$

The set $\mathfrak{F}^{2}$ of points $(0.2)$ corresponding to the values $\left|Z_{k}\right|=1, k=1, \cdots, n$, constitutes the so-called Bergman-Šilov boundary surface of $\mathfrak{B}$ on which the maximum principle holds for functions regular in $\overline{\mathfrak{B}}$ (see [1]). We shall also assume that for every $\left|Z_{k}^{(0)}\right|<1, \lambda_{k}^{(0)}, k=1, \cdots, n$, and for sufficiently small $\sigma>0$, the set of points (0.2) which correspond to the values

$$
\left|Z_{k}-Z_{k}^{(0)}\right|<\sigma, \quad\left|\lambda_{k}-\lambda_{k}^{(0)}\right|<\sigma
$$

of the parameters contain all the points of $b^{3}$ lying sufficiently near the point

$$
\boldsymbol{z}_{1}^{(0)}=h_{1 k}\left(Z_{k}^{(0)}, \lambda_{k}^{(0)}\right), \quad \boldsymbol{z}_{k}^{(0)}=h_{2 k}\left(Z_{k}^{(0)}, \lambda_{k}^{(0)}\right) .
$$

The set of points of Iour-dimensional space of the form

$$
z_{1}=g_{1}(\zeta), z_{2}=g_{2}(\zeta), \zeta \in \bar{D},
$$

where $\mathfrak{D}$ is a domain in the $\zeta$-plane, and the expressions on the righthand sides of (0.5) are holomorphic functions of $\zeta$ in $D$ and continuous in $\bar{D}$, is called an analytic surface.

The set of points which corresponds to the values $\zeta \in \partial(D))^{3}$ will be

$3 \partial(\mathfrak{D})=$ boundary of $\mathfrak{D}$ 
called the boundary of the surface.

The complement of $\mathfrak{B}$ with respect to the whole space will be called $\mathfrak{F}_{0}$.

1. Bounds for the function $f\left(z_{1}, z_{2}\right)$ on the analytic surface. Let $\mathfrak{B}$ be a domain described in $\S 0$ and let $\mathbb{S}_{0}^{2}$ denote an analytic surface of the form (0.5). We assume that $\mathbb{S}_{0}^{2}$ has common points with $\mathfrak{B}$ and its whole boundary lies in $\mathfrak{F}_{0}$. Further, let the intersection $\mathbb{S}_{0}^{2}$ with $\mathfrak{B}$ satisfy the following conditions:

$1^{\circ}$. The intersection is a segment

$$
\mathbb{S}^{2}=\mathbb{S}_{0}^{2} \cap \mathfrak{B}=\left\{\left(z_{1}, z_{2}\right): z_{1}=g_{1}(\zeta), z_{2}=g_{2}(\zeta),|\zeta|<1\right\} \text {. }
$$

Here $g_{1}(\zeta), g_{2}(\zeta)$ are analytic functions which are regular in $|\zeta|<1$ and continuous in $|\zeta| \leqq 1$.

$2^{\circ}$. The boundary curve $\mathfrak{g}^{1}$ of $\mathbb{S}^{2}$ is the intersection $\overline{\mathbb{S}}_{0}^{2}$ with $\mathfrak{b}^{3}$. We assume that

$$
g^{1}=\left\{\left(z_{1}, z_{2}\right): z_{1}=g_{1}\left(e^{i \varphi}\right), z_{2}=g_{2}\left(e^{i \varphi}\right), 0 \leqq \varphi \leqq 2 \pi\right\}
$$

can be divided into $J$ parts

$$
\begin{gathered}
g_{j}^{1}=\left\{\left(z_{1}, z_{2}\right): z_{1}=g_{1}\left(e^{i \varphi}\right), z_{2}=g_{2}\left(e^{i \varphi}\right), \varphi_{j} \leqq \varphi \leqq \varphi_{j+1}\right\}, \\
j=1, \cdots, J, \varphi_{1}<\varphi_{2}<\cdots<\varphi_{J+1}=\varphi_{1}+2 \pi,
\end{gathered}
$$

so that $\mathrm{g}_{j}^{1} \in \mathrm{e}_{k_{j}}^{3}, k_{j_{1}} \neq k_{j_{2}}$ for $j_{1} \neq j_{2}$ and only the points

$$
\left(g_{1}\left(e^{i \varphi_{j}}\right), g_{2}\left(e^{i \varphi_{j}}\right)\right), j=1, \cdots, J,
$$

belong to $\mathfrak{F}^{2}$.

$3^{\circ}$. Every point of $\mathfrak{g}_{j}^{1}$ lies in a certain lamina, say

$$
\Im_{k_{j}}^{2}\left(\lambda_{k_{j}}\right)=\left\{\left(z_{1}, z_{2}\right): z_{1}=h_{1 k_{j}}\left(Z_{k_{j}}, \lambda_{k_{j}}\right), z_{2}=h_{2 k_{j}}\left(Z_{k_{j}}, \lambda_{k_{j}}\right)\right\} \text {. }
$$

Hence, by (0.3) and (0.4), functions $\lambda_{k_{j}}=\lambda_{k_{j}}(\varphi)$ and $Z_{k_{j}}=Z_{k_{j}}(\varphi), \varphi_{j} \leqq$ $\varphi \leqq \varphi_{j+1}$, exist such that

$$
\begin{aligned}
& g_{j}^{1}=\left\{\left(z_{1}, z_{2}\right): z_{1}=h_{1 k_{j}}\left(Z_{k_{j}}(\varphi), \lambda_{k_{j}}(\varphi)\right), z_{2}=h_{2 k_{j}}\left(Z_{k_{j}}(\varphi), \lambda_{k_{j}}(\varphi)\right),\right. \\
&\left.\varphi_{j} \leqq \varphi \leqq \varphi_{j+1}\right\} .
\end{aligned}
$$

We assume that $\lambda_{k j}(\varphi), Z_{k j}(\varphi), j=1, \cdots, J$, are continuous and that $\lambda_{k j}(\varphi)$ are also monotone in the intervals $\left\langle\varphi_{j}, \varphi_{j+1}\right\rangle$. Therefore, the derivatives $\lambda_{k j}^{\prime}(\varphi)$ exist almost everywhere.

$4^{\circ}$. Since $\lambda_{k_{j}}(\varphi)$ are monotone in $\left\langle\varphi_{j}, \varphi_{j+1}\right\rangle$, there exist inverse functions $\varphi_{j}\left(\lambda_{k_{j}}\right)$ in the intervals $\left\langle\alpha_{j}, \beta_{j}\right\rangle=\lambda_{k_{j}}\left(\left\langle\varphi_{j}, \varphi_{j+1}\right\rangle\right)$. The derivatives 
$\varphi_{j}^{\prime}\left(\lambda_{k j}\right)$ also exist in $\left\langle\alpha_{j}, \beta_{j}\right\rangle$ almost everywhere. We shall assume that

$$
\left|\varphi_{j}^{\prime}\left(\lambda_{k_{j}}\right)\right| \leqq Q,
$$$$
j=1, \cdots, J \text {. }
$$

$5^{\circ}$. The intersection $\mathscr{S}_{0}^{2}$ is such that the expressions $1-\left|Z_{k j}(\varphi)\right|$ go to zero no faster than some positive power of $\varphi-\varphi_{j}$ or $\varphi-\varphi_{j+1}$ if $\varphi \rightarrow \varphi_{j}+$ or $\varphi \rightarrow \varphi_{j+1}-$, respectively.

The hypotheses $1^{\circ}, 2^{\circ}$, and $3^{\circ}$ are the same as hypotheses 1,2 , and 3 in [4], p. 188. Instead of hypothesis 6, [4] we have the weaker hypothesis $5^{\circ} .^{4}$

We define now a family of functions in a domain $\mathfrak{B}$. The function $f\left(z_{1}, z_{2}\right)$ defined in $\overline{\mathfrak{B}}$ will be called the function of the family $\mathscr{F}_{\mathfrak{B}}\left(\mathbb{S}_{0}^{2}, P\right), P>0$, if it satisfies the following conditions:

$1^{\circ 0} f\left(z_{1}, z_{2}\right)$ is regular in the set $\mathfrak{B}_{1}=\overline{\mathfrak{B}} \mid \mathfrak{F}^{2}$ continuous in $\mathfrak{B}_{2}=$ $\mathfrak{B}_{1} \cup \mathfrak{g}^{1} \cap \mathfrak{F}^{2}$.

$2^{\circ \circ} . f\left(z_{1}, z_{2}\right) \neq 0$ in $\mathfrak{B}_{2}$.

$3^{\circ \circ}$. On almost every lamina $\mathfrak{F}_{k_{j}}^{2}\left(\lambda_{k_{j}}\right), \alpha_{j} \leqq \lambda_{k_{j}} \leqq \beta_{j}$, the function $f\left(z_{1}, z_{2}\right)=f\left(h_{1 k_{j}}\left(Z_{k_{j}}, \lambda_{k_{j}}\right), h_{2 k_{j}}\left(Z_{k_{j}}, \lambda_{k_{j}}\right)\right)$ considered as a function of one variable $Z_{k_{j}}$ in the circle $\left|Z_{k_{j}}\right|<1$ is a mean multivalent function of the order $p_{j}\left(\lambda_{k_{j}}\right)$ in the sense of Biernacki, see [5], [7]. ${ }^{5}$

$4^{\circ 0}$. The functions $p_{j}\left(\lambda_{k_{j}}\right)$ may grow to infinity, but in such a way that they are square-integrable in $\left\langle\alpha_{j}, \beta_{j}\right\rangle$.

$5^{\circ 0}$

$$
\sum_{j=1}^{J}\left(\frac{1}{2 \pi} \int_{\alpha_{j}}^{\beta_{j}} p_{j}^{2}\left(\lambda_{k_{j}}\right) d \lambda_{k_{j}}\right)^{1 / 2} \leqq J P .^{6}
$$

DeFinition. Every $f\left(z_{1}, z_{2}\right)$ which belongs to $\mathscr{F}_{\mathfrak{B}}\left(\mathbb{S}_{0}^{2}, P\right)$ will be called. a mean multivalent function of the order $P$ with respect to $\mathbb{S}_{0}^{2}$.

We set

$$
\begin{aligned}
& l=\min \left[1, \min _{\substack{\alpha, \leq \lambda_{k j} \leq \beta_{j} \\
j=1, \cdots \cdots, J}}\left|f\left(h_{1 k_{j}}\left(0, \lambda_{k_{j}}\right), h_{2 k_{j}}\left(0, \lambda_{k_{j}}\right)\right)\right|\right], \\
& L=\max \left[1, \max _{\substack{\alpha_{j} \leq \lambda_{k_{j}} \leq \beta_{j} \\
j=1, \ldots, J_{j},}}\left|f\left(h_{1 k_{j}}\left(0, \lambda_{k_{j}}\right), h_{2 k_{j}}\left(0, \lambda_{k_{j}}\right)\right)\right|\right] .
\end{aligned}
$$

${ }^{4}$ From hypothesis 6 it follows that $1-\left|Z_{k_{j}}(\varphi)\right|$ must go to zero no faster than $1 / \log \left|\varphi-\varphi_{j}\right|$.

5 A function $f(z)$ regular in $|z|<1$ is called mean multivalent of order $p$ in the sence of Biernacki if

$$
p(R)=\frac{1}{2 \pi} \int_{0}^{2 \pi} n\left(R e^{i \theta}\right) d \theta \leqq p
$$

for every positive number $R$. Here $n\left(R e^{i \theta}\right)$ designate the number of $R e^{i \theta}$ - points of $f(z)$, in $|z|<1$.

${ }_{6}$ The integrals here are in the sense of Lebesgue. 
Theorem 1. For every $\varepsilon>0$ there exists $r_{0}, 0<r_{0}<1$, so that at every point of $G^{2}$, say at $z_{1}^{0}=g_{1}\left(\zeta_{0}\right), z_{2}^{0}=g_{2}\left(\zeta_{0}\right)$, the function $f\left(z_{1}, z_{2}\right) \in$ $\mathscr{F}_{33}\left(\mathbb{S}_{0}^{2}, P\right)$ satisfies the inequality

$\left(^{*}\right)\left(e^{-\varepsilon} l\left(\frac{1-r}{1+r}\right)^{2 J P Q}\right)^{\left(1+\left|\zeta_{0}\right|\right) /\left(1-\left|\zeta_{0}\right|\right)} \leqq\left|f\left(z_{1}^{0}, z_{2}^{0}\right)\right| \leqq\left(e^{\varepsilon} L\left(\frac{1+r}{1-r}\right)^{2 J P Q}\right)^{\left(1+\mid \zeta_{0} !\right) /\left(1-\left|\zeta_{0}\right|\right.}$ for every $r \geqq r_{0}$.

Proof. First, we prove the last inequality in $\left(^{*}\right)$. Let $\varepsilon>0$. By hypothesis $5^{\circ}$ there exist positive numbers $a_{j}$ and $b_{j}$ such that

$$
\lim _{\varphi \rightarrow \varphi_{j+}} \frac{1-\left|Z_{k_{j}}(\varphi)\right|}{\left(\varphi-\varphi_{j}\right)^{\alpha_{j}}} \text { and } \lim _{\varphi \rightarrow \varphi_{j+1}} \frac{1-\left|Z_{k_{j}}(\varphi)\right|}{\left(\varphi_{j+1}-\varphi\right)^{b_{j}}}
$$

are different from zero. ${ }^{7}$ Hence, there are positive numbers, say $A_{j}$ and $B_{j}$, and a positive number $\eta^{\prime}$ such that

$$
1-\left|Z_{k_{j}}(\varphi)\right|>A_{j}\left(\varphi-\varphi_{j}\right)^{a_{j}}
$$

and

$$
1-\left|Z_{k_{j}}(\varphi)\right|>B_{j}\left(\varphi_{j+1}-\varphi\right)^{b_{j}}
$$

for $0<\varphi-\varphi_{j}<\eta^{\prime}$ or $0<\varphi_{j+1}-\varphi<\eta^{\prime}$, respectively. Further, since the functions

$$
\omega_{1 j}(x)=x \log ^{2} \frac{2}{A_{j} x^{a_{j}}}+2 a_{j} x \log \frac{2}{A_{j} x^{a_{j}}}+2 a_{j}^{2} x
$$

and

$$
\omega_{2 j}(x)=x \log ^{2} \frac{2}{B_{j} x^{b_{j}}}+2 b_{j} x \log \frac{2}{B_{j} x^{b_{j}}}+2 b_{j}^{2} x
$$

go to zero for $x \rightarrow 0+$, there exists an $\eta^{\prime \prime}>0$ such that

$$
\omega_{1 j}(x)<\frac{\pi \varepsilon^{2}}{8 Q J^{2} P^{2}}, \quad \omega_{2 j}(x)=\frac{\pi \varepsilon^{2}}{8 Q J^{2} P^{2}}
$$

for $0<x<\eta^{\prime \prime}$. If we set now

$$
\eta=\min \left(\eta^{\prime}, \eta^{\prime \prime}\right)
$$

then the inequalities (1.2), (1.2') and (1.3), respectively, are satisfied for $0<\varphi-\varphi_{j}<\eta, 0<\varphi_{j+1}-\varphi<\eta$ and $0<x<\eta$.

Let $\left(z_{1}^{0}, z_{2}^{0}\right) \in \mathbb{S}^{2}$. Then $z_{1}^{0}=g_{1}\left(\zeta_{0}\right), z_{2}^{0}=g_{2}\left(\zeta_{0}\right)$. We consider now the function $f\left(z_{1}, z_{2}\right)$ in the segment $\overline{\bar{S}^{2}}$, i.e., $f\left(g_{1}(\zeta), g_{2}(\zeta)\right)$ in $|\zeta| \leqq 1$. Considered as a function of $\zeta$ it is regular in $|\zeta|<1$ and continuous in

$7 a_{j}, b_{j}$ may be infinite. 
$|\zeta| \leqq 1$. For $\zeta=e^{i \varphi}$ it has the following bounds

$$
\begin{aligned}
\left|f\left(g_{1}\left(e^{i \varphi}\right), g_{2}\left(e^{i \varphi}\right)\right)\right| & \leqq L\left(\frac{1+\left|Z_{k_{j}}(\varphi)\right|}{1-\left|Z_{k_{j}}(\varphi)\right|}\right)^{2 p_{j}\left(\lambda_{k_{j}}(\varphi)\right)} \\
& \text { for } \varphi \in\left(\varphi_{j}, \varphi_{j+1}\right), \quad j=1, \cdots, J .
\end{aligned}
$$

This is a consequence of the fact that $f\left(z_{1}, z_{2}\right)$ assumes at the point $\left(g_{1}\left(e^{i \varphi}\right), g_{2}\left(e^{i \varphi}\right)\right)$ the values of the multivalent functions $f\left(h_{1 k_{j}}\left(Z_{k_{\mathrm{g}}}, \lambda_{k_{\mathrm{g}}}\right)\right.$, $h_{2 k_{j}}\left(Z_{k_{j}}, \lambda_{k_{j}}\right)$ ) (of order $p_{j}\left(\lambda_{k_{j}}(\varphi)\right)$ ) at the point $Z_{k j}(\varphi)$, see [7], p. 116. We divide the line $\mathrm{g}_{j}^{1}$ into two parts $\check{\mathrm{g}}_{j}^{1}$ and $\check{\mathrm{g}}_{j}^{1}$ as follows

$$
\begin{aligned}
& \check{\mathrm{g}}_{j}^{1}=\left\{\left(z_{1}, z_{2}\right): z_{1}=g_{1}\left(e^{i \varphi}\right), z_{2}=g_{2}\left(e^{i \varphi}\right), \varphi \in\left\langle\varphi_{j}+\eta, \varphi_{j+1}-\eta\right\rangle\right\}, \\
& \check{\mathrm{g}}_{j}^{1}=\left\{\left(z_{1}, z_{2}\right): z_{1}=g_{1}\left(e^{i \varphi}\right), z_{2}=g_{2}\left(e^{i \varphi}\right), \varphi \in\left\langle\varphi_{j}, \varphi_{j}+\eta\right) \cup\left(\varphi_{j+1}-\eta, \varphi_{j+1}\right\rangle\right\} .
\end{aligned}
$$

It is easy to see that $r_{0}$ exists such that for every point $\left(g_{1}\left(e^{i \varphi}\right), g_{2}\left(e^{i \varphi}\right)\right)$ the inequality $\left|Z_{k_{j}}(\varphi)\right| \leqq r_{0}$ holds (this follows from the continuity of the functions $\left.Z_{k}(\varphi)\right)$. Therefore, for these points, the inequalities (1.4) give the following bounds

$$
\left|f\left(g_{1}\left(e^{i \varphi}\right), g_{2}\left(e^{i \varphi}\right)\right)\right| \leqq L\left(\frac{1+r}{1-r}\right)^{2 p_{j}\left(\lambda_{k_{j}}(\varphi)\right)}
$$

for every $r \geqq r_{0}$ and for $\varphi \in\left\langle\varphi_{j}+\eta, \varphi_{j+1}-\eta\right\rangle, j=1, \cdots, J$. On the complementary part of $\mathrm{g}^{18}$ we have the inequalities

$$
\left|f\left(g_{1}\left(e^{i \varphi}\right), g_{2}\left(e^{i \varphi}\right)\right)\right| \leqq L\left(\frac{2}{A_{j}\left(\varphi-\varphi_{j}\right)^{\alpha_{j}}}\right)^{2 p_{j}\left(\lambda_{k_{j}}(\varphi)\right)}
$$

for $\varphi \in\left(\varphi_{j}, \varphi_{j}+\eta\right)$,

and

$$
\begin{aligned}
& \left|f\left(g_{1}\left(e^{i \varphi}\right), g_{2}\left(e^{i \varphi}\right)\right)\right| \leqq L\left(\frac{2}{B_{j}\left(\varphi_{j+1}-\varphi\right)^{b_{j}}}\right)^{2 p_{j}\left(\lambda_{k_{j}}(\varphi)\right)} \\
& \text { for } \varphi \in\left(\varphi_{j+1}-\eta, \varphi_{j+1}\right) .
\end{aligned}
$$

This follows from (1.4), (1.2) and (1.2').

Applying now the Poisson formula to the function $\log \left|f\left(g_{1}(\zeta), g_{2}(\zeta)\right)\right|$, which is harmonic in $|\zeta|<1$ and continuous in $|\zeta| \leqq 1$, and using the inequalities (1.5), (1.6) and (1.6') we obtain

$$
\begin{aligned}
\log \left|f\left(z_{1}^{0}, z_{2}^{0}\right)\right|= & \frac{1}{2 \pi} \int_{0}^{2 \pi} \log \left|f\left(g_{1}\left(e^{i \varphi}\right), g_{2}\left(e^{i \varphi}\right)\right)\right| r e \frac{e^{i \varphi}+\zeta_{0}}{e^{i \varphi}-\zeta_{0}} d \varphi \\
= & \sum_{j=1}^{J}\left[\frac{1}{2 \pi} \int_{\varphi_{j}+\eta}^{\varphi_{j+1}-\eta} \log L\left(\frac{1+r}{1-r}\right)^{2 p_{j}\left(\lambda_{k_{j}}(\varphi)\right)} r e \frac{e^{i \varphi}+\zeta_{0}}{e^{i \varphi}-\zeta_{0}} d \varphi\right. \\
& +\frac{1}{2 \pi} \int_{\varphi_{j}}^{\varphi_{j+1}} \log L\left(\frac{2}{A_{j}\left(\varphi-\varphi_{j}\right)^{a_{j}}}\right)^{2_{j}\left(\lambda_{k_{j}}(\varphi)\right)} r e \frac{e^{i \varphi}+\zeta_{0}}{e^{i \varphi}-\zeta_{0}} d \varphi \\
& \left.+\frac{1}{2 \pi} \int_{\varphi_{j+1}-\eta}^{\varphi_{j+1}} \log L\left(\frac{2}{B_{j}\left(\varphi_{j+1}-\varphi\right)^{b_{j}}}\right)^{2_{j} p_{j}^{\left(\lambda_{k}(\varphi)\right)}} r e \frac{e^{i \varphi}+\zeta_{0}}{e^{i \varphi}-\zeta_{0}} d \varphi\right]
\end{aligned}
$$

8 Except for the points $\left(g_{1}\left(e^{i \varphi_{j}}\right), g_{2}\left(e^{i \varphi_{j}}\right)\right)$. 
Interchanging the variables of integration and applying the Schwarz inequality to the last two integrals we get

$$
\begin{aligned}
& \log \left|f\left(z_{1}^{0}, z_{2}^{0}\right)\right| \leqq \frac{1+\left|\zeta_{0}\right|}{1-\left|\zeta_{0}\right|} \sum_{j=1}^{J}\left[\frac{1}{2 \pi} \int_{\varphi_{j}}^{\varphi_{j+1}} \log L d \varphi\right. \\
& \quad+2 \log \left(\frac{1+r}{1-r}\right)\left|\frac{1}{2 \pi} \int_{\lambda_{k_{j}}\left(\varphi_{j}+\eta\right)}^{\lambda_{k_{j}}\left(\varphi_{j+1}-\eta\right)} p_{j}\left(\lambda_{k_{j}}\right) \varphi_{j}^{\prime}\left(\lambda_{k_{j}}\right) d \lambda_{k_{j}}\right| \\
& \quad+\frac{2}{2 \pi} \sqrt{\left|\int_{\lambda_{k_{j}}(\varphi)}^{\lambda_{k_{j}\left(\varphi_{j}+\eta\right)}} p_{j}^{2}\left(\lambda_{k_{j}}\right) \varphi_{j}^{\prime}\left(\lambda_{k_{j}}\right) d \lambda_{k_{j}}\right|} \sqrt{\int_{\varphi_{j}}^{\varphi_{j}+\eta} \log ^{2} \frac{2}{A_{j}\left(\varphi-\varphi_{j}\right)^{a_{j}}} d \varphi} \\
& \left.\quad+\frac{2}{2 \pi} \sqrt{\left|\int_{\lambda_{k_{j}}\left(\varphi_{j+1}-\eta\right)}^{\lambda_{k_{j}}\left(\varphi_{j+1}\right)} p_{j}^{2}\left(\lambda_{k_{j}}\right) \varphi_{j}^{\prime}\left(\lambda_{k_{j}}\right) d \lambda_{k_{j}}\right|} \sqrt{\int_{\varphi_{j+1}-\eta}^{\varphi_{j+1}} \log ^{2} \frac{2}{B_{j}\left(\varphi_{j+1}-\varphi\right)^{b_{j}}} d \varphi}\right] .
\end{aligned}
$$

Evaluating the integrals

$$
\int_{\varphi_{j}}^{\varphi_{j}+\eta} \log ^{2} \frac{2}{A_{j}\left(\varphi-\varphi_{j}\right)^{a_{j}}} d \varphi \text { and } \int_{\varphi_{j+1}-\eta}^{\varphi_{j+1}} \log ^{2} \frac{2}{B_{j}\left(\varphi_{j+1}-\varphi\right)^{b_{j}}} d \varphi \text {, }
$$

using hypotheses $4^{\circ}, 4^{\circ \circ}$ and $5^{\circ 09}$ and inequalities (1.3), we have

$$
\begin{aligned}
\log \left|f\left(z_{1}^{0}, z_{2}^{0}\right)\right| \leqq & \frac{1+\left|\zeta_{0}\right|}{1+\left|\zeta_{0}\right|}\left[\log L+Q \cdot 2 \log \left(\frac{1+r}{1-r}\right) \sum_{j=1}^{J} \frac{1}{2 \pi} \int_{\alpha_{j}}^{\beta_{j}} p_{j}\left(\lambda_{k_{j}}\right) d \lambda_{k_{j}}\right. \\
& +\frac{2}{2 \pi} \sqrt{\bar{Q}} \sum_{j=1}^{J}\left(\sqrt{\frac{1}{2 \pi} \int_{\lambda_{k_{j}}\left(\varphi_{j}\right)}^{\lambda_{k_{j}\left(\varphi_{j}+\eta\right)}} p_{j}^{2}\left(\lambda_{k_{j}}\right) d \lambda_{k_{j}}} \cdot \sqrt{\omega_{1 j}(\eta)}\right. \\
& \left.\quad+\sqrt{\frac{1}{2 \pi} \int_{\lambda_{k_{j}}\left(\varphi_{j}{ }^{\left(\varphi_{j}-\eta\right)}\right.}^{\left.\lambda_{j}\right)} p_{j}^{2}\left(\lambda_{k_{j}}\right) d \lambda_{k_{j}}} \cdot \sqrt{\omega_{2 j}(\eta)}\right) \\
\leqq & \frac{1+\left|\zeta_{0}\right|}{1-\left|\zeta_{0}\right|}\left[\log L+2 Q J P \log \left(\frac{1+r}{1-r}\right)\right. \\
& \left.+\frac{2}{\sqrt{2 \pi}} \sqrt{Q} \cdot \frac{\sqrt{\pi} \cdot \varepsilon}{2 \sqrt{2} \sqrt{Q} J P} \cdot 2 J P\right] \\
= & \frac{1+\left|\zeta_{0}\right|}{1-\left|\zeta_{0}\right|}\left(\log L\left(\frac{1+r}{1-r}\right)^{2 P Q J}+\varepsilon\right) .
\end{aligned}
$$

Therefore, finally

$$
\left|f\left(z_{1}^{0}, z_{2}^{0}\right)\right| \leqq\left(e^{\varepsilon} L\left(\frac{1+r}{1-r}\right)^{2 J P Q}\right)^{\left(1+\left|\zeta_{0}\right|\right) /\left(1+\left|\zeta_{0}\right|\right)}
$$

which is the first inequality of $(*)$. We notice now that

${ }^{9}$ From $5^{\circ \circ}$ and the Schwarz inequality, we get

$$
\begin{aligned}
\sum_{j=1}^{J}\left|\frac{1}{2 \pi} \int_{\lambda_{k_{j}} \varphi^{\left(\varphi_{j}+\eta\right)}}^{\lambda_{k_{j}^{(}\left(\varphi_{j+1}-\eta\right)}} p_{j}\left(\lambda_{k_{j}}\right) d \lambda_{k_{j}}\right| & \leqq \sum_{j=1}^{J} \frac{1}{2 \pi} \int_{\alpha_{j}}^{\beta_{j}} p_{j}\left(\lambda_{k_{j}}\right) d \lambda_{k_{j}} \\
& \leqq \sum_{j=1}^{J} \frac{1}{2 \pi} \sqrt{\beta_{j}-\alpha_{j}} / \overline{\int_{\alpha_{j}}^{\beta_{j}} p_{j}^{2}\left(\lambda_{k_{j}}\right) d \lambda_{k_{j}}} \leqq \sum_{j=1}^{J}\left(\frac{1}{2 \pi} \int_{\alpha_{j}}^{\beta_{j}} p_{j}^{2}\left(\lambda_{k_{j}}\right) d \lambda_{k_{j}}\right)^{1 / 2} \leqq J P .
\end{aligned}
$$




$$
\frac{1}{f\left(z_{1}, z_{2}\right)} \in \mathscr{F}_{\mathfrak{B}}\left(\mathcal{S}_{0}^{2}, P\right) \text { if } f\left(z_{1}, z_{2}\right) \in \mathscr{F}_{\mathfrak{B}}\left(\mathcal{S}_{0}^{2}, P\right)^{10}
$$

Moreover,

$$
\begin{aligned}
& \max \left(1, \max _{\alpha_{j} \leqq \lambda_{k_{j} \leqq \beta_{j}}}\left|\frac{1}{f\left(h_{1 k_{j}}\left(0, \lambda_{k_{j}}\right), h_{2 k_{j}}\left(0, \lambda_{k_{j}}\right)\right)}\right|\right) \\
& =\max \left(1, \frac{1}{\min _{\alpha_{j} \leqq \lambda_{k_{j}} \leqq \beta_{j}} \mid f\left(h_{1 k_{j}}\left(0, \lambda_{k_{j}}\right), h_{2 k_{j}}\left(0, \lambda_{k_{j}}\right) \mid\right.}\right) \\
& \leqq \frac{1}{\min (\underbrace{}_{\alpha_{j} \leqq \lambda_{k_{j}} \leqq \beta_{j}} \min _{1} \mid f\left(h_{1 k_{j}}\left(0, \lambda_{k_{j}}\right), h_{2 k_{j}}\left(0, \lambda_{k_{j}}\right) \mid\right)}=\frac{1}{l} .
\end{aligned}
$$

Applying the inequality (1.7) to the function $1 / f\left(z_{1}, z_{2}\right)$, we obtain the inequality

$$
\frac{1}{f\left(z_{1}, z_{2}\right)} \leqq\left(e^{\varepsilon} \frac{1}{l}\left(\frac{1+r}{1-r}\right)^{2 J P Q}\right)^{\left(1+\left|\zeta_{0}\right|\right) /\left(1-\left|\zeta_{0}\right|\right)}
$$

for $r \geqq r_{0} ; r_{0}$ is here the same as in (1.7), because it is independent of the function. From (1.8) we have

$$
\left|f\left(z_{1}^{0}, z_{2}^{0}\right)\right| \geqq\left(e^{-\varepsilon} l\left(\frac{1+r}{1-r}\right)^{2 J P Q}\right)^{\left(1+\left|\zeta_{0}\right|\right) /\left(1-\left|\zeta_{0}\right|\right)}
$$

The inequalities (1.7) and (1.9) give the conclusion of the theorem.

REMARK 1. Modifying the definition of the family $\mathscr{F}_{B}\left(\mathbb{S}_{0}^{2}, P\right)$, we obtain somewhat simpler analogous results. Instead of hypothesis $4^{\circ \circ}$ we assume that the function $p_{j}\left(\lambda_{k_{j}}(\varphi)\right)$ considered as a function of the variable $\varphi$ is square-integrable in the interval $\left\langle\varphi_{j}, \varphi_{j+1}\right\rangle$, and we replace condition $5^{\circ \circ}$ by the condition

$$
\sum_{j=1}^{J}\left(\frac{1}{2 \pi} \int_{\varphi_{j}}^{\varphi_{j+1}} p_{\jmath}^{2}\left(\lambda_{k_{j}}(\varphi)\right) d \varphi\right)^{1 / 2} \leqq J P
$$

The assumptions that $\lambda_{k_{j}}(\varphi)$ are continuous and monotonic and that $\left|\varphi^{\prime}\left(\lambda_{k_{j}}\right)\right| \leqq Q$ are now superfluous. The family of functions which satisfy these conditions will be called $\mathscr{F}_{\mathfrak{B}}^{*}\left(\mathbb{S}_{0}^{2}, P\right)$. For functions of that family we can prove

TheOREM 1'. For every $\varepsilon>0$ there exists $r_{0}, 0<r_{0}<1$, such that for every point $\left(z_{1}^{0}, z_{2}^{0}\right) \in \mathbb{S S}^{2}$ and for every $f\left(z_{1}, z_{2}\right) \in \mathscr{F}_{\mathfrak{B}}^{*}\left(\mathbb{S}_{0}^{2}, P\right)$ the inequality

$$
\left(l\left(\frac{1-r}{1+r}\right)^{2 J P} e^{-\varepsilon}\right)^{\left(1+\left|\zeta_{0}\right|\right) /\left(1-\left|\zeta_{0}\right|\right)} \leqq\left|f\left(z_{1}^{0}, z_{2}^{0}\right)\right| \leqq\left(L\left(\frac{1+r}{1-r}\right)^{2 J P} e^{\varepsilon}\right)^{\left(1+\left|\zeta_{0}\right|\right) /\left(1-\left|\zeta_{0}\right|\right)}
$$

10 If $f(z) \neq 0$ and is mean-multivalent of order $p$ in the sense of Biernacki, then $1 / f(z)$ has the same property. 
holds for every $r \geqq r_{0}$.

The number $r_{0}$ is chosen in the following way. Let $\varepsilon>0$ be an arbitrary number. The number $\eta^{\prime}$ is chosen in the same way as in the proof given above; $\eta^{\prime \prime}$ is such that

$$
\sqrt{\omega_{1 j}(x)}<\frac{\pi \varepsilon^{2}}{8 J^{2} P^{2}} \text { and } \sqrt{\omega_{2 j}(x)}<\frac{\pi \varepsilon^{2}}{8 J^{2} P^{2}}
$$

for $0<x<\eta^{\prime \prime}$. We set $\eta=\min \left(\eta^{\prime}, \eta^{\prime \prime}\right)$ and for $\eta$ we choose a number $r_{0}$ as previously.

REMARK 2. If the surface $\mathbb{S}_{0}^{2}$ intersects only one boundary segment, say $\mathfrak{e}_{k}^{3}$, and the line of intersection $\mathrm{g}^{1}$ lies $\mathfrak{e}_{k r_{0}}^{3}$, where

$$
\mathfrak{e}_{k r_{0}}^{3}=\left\{\left(z_{1}, z_{2}\right): z_{1}=h_{1 k}\left(Z_{k}, \lambda_{k}\right),\left|Z_{k}\right| \leqq r_{0}\right\},
$$

then

$$
\left(l\left(\frac{1-\mathrm{r}}{1+r}\right)^{2 P Q}\right)^{\left(1+\left|\zeta_{0}\right|\right) /\left(1-\left|\zeta_{0}\right|\right)} \leqq\left|f\left(z_{1}^{0}, z_{2}^{0}\right)\right| \leqq\left(L\left(\frac{1+r}{1-r}\right)^{2 P Q}\right)^{\left(1+\left|\zeta_{0}\right|\right) /\left(1-\left|\zeta_{0}\right|\right)}
$$

for every $r \geqq r_{0}$ in the case that $f\left(z_{1}, z_{2}\right) \in \mathscr{F}_{\mathfrak{B}}\left(\mathbb{S}_{2}^{2}, P\right)$ and

$$
\left(l\left(\frac{1-r}{1+r}\right)^{2 P}\right)^{\left(1+\left|\zeta_{0}\right|\right) /\left(1-\left|\zeta_{0}\right|\right)} \leqq\left|f\left(z_{1}^{0}, z_{2}^{0}\right)\right| \leqq\left(L\left(\frac{1+r}{1-r}\right)^{2 P}\right)^{\left(1+\left|\zeta_{0}\right|\right) /\left(1-\left|\zeta_{0}\right|\right)}
$$

if $f\left(z_{1}, z_{2}\right) \in \mathscr{F}_{\mathfrak{B}}^{*}\left(\mathcal{S}_{0}^{2}, P\right)$.

Indeed, for every $\varphi$ for which $\left(g_{1}\left(e^{i \varphi}\right), g_{2}\left(e^{i \varphi}\right)\right) \in e_{k r_{0}}^{3}$, the corresponding point $Z_{k}(\varphi)$ satisfies the inequality

$$
\left|Z_{k}(\varphi)\right| \leqq r_{0},
$$

and therefore

$$
\left|f\left(g_{1}\left(e^{i \varphi}\right), g_{2}\left(e^{i \varphi}\right)\right)\right| \leqq L\left(\frac{1+r}{1-r}\right)^{2 p_{k}\left(\lambda_{k}(\varphi)\right)}
$$

for $\varphi \in\langle 0,2 \pi\rangle$. Applying, as previously, the Poisson formula and using the inequality (1.12), we obtain (1.11) in the first case and $\left(1,11^{\prime}\right)$ in the second.

REMARK 3. The result of Theorems 1 and $1^{\prime}$ can be obtained without requiring that $\mathfrak{B}$ is an analytic polyhedron. It is sufficient to assume that the part of the boundary which intersects by $\mathbb{S}_{0}^{2}$ is a sum of the analytic hypersurfaces mentioned in $\S 0$. Concerning the complementary part of the boundary no special hypotheses are needed.

REMARK 4. The lower and upper bounds of $|f|$ are expressed in terms of the minimum and the maximum of $|f|$ on the manifold 


$$
\bigcup_{j=1}^{J} \bigcup_{\lambda_{j} \in\left\langle\alpha_{j}, \beta_{j}\right\rangle}\left(h_{1 k_{j}}\left(0, \lambda_{k_{j}}\right), h_{2 k_{j}}\left(0, \lambda_{k_{j}}\right)\right) \text {. }
$$

We note that analogous bounds can be obtained in term of the minimum and the maximum of $|f|$ on a manifold

$$
\bigcup_{j=1}^{J} \bigcup_{\lambda_{k_{j}} \in<\alpha_{j}, \beta_{j}>}\left(h_{1 k_{j}}\left(Z_{k_{j}}\left(\lambda_{k_{j}}\right), \lambda_{k_{j}}\right), h_{2 k_{j}}\left(Z_{k_{j}}\left(\lambda_{k_{j}}\right), \lambda_{k_{j}}\right)\right),
$$

where $\left|Z_{k_{j}}\left(\lambda_{k_{j}}\right)\right|<1$ and $Z_{k_{j}}\left(\lambda_{k_{j}}\right)$ are continuously differentiable functions of $\lambda_{k,} \in\left\langle\alpha_{j}, \beta_{j}\right\rangle$. These new bounds are obtained by changing the parametric representations of $\mathfrak{e}_{k_{j}}^{3}, j=1, \cdots, J$, as follows:

$$
\mathbf{e}_{k_{j}}^{3}=\left\{\left(z_{1}, z_{2}\right): z_{1}=\widetilde{h}_{1 k_{j}}\left(\widetilde{Z}_{k_{j}}, \lambda_{k_{\mathrm{g}}}\right), z_{2}=\widetilde{h}_{2 k_{j}}\left(\widetilde{Z}_{k_{j}}, \lambda_{k_{\mathrm{j}}}\right)\right\},
$$

$\left|\widetilde{Z}_{k j}\right| \leqq 1$, where

$$
\widetilde{h}_{k_{j}}\left(\widetilde{Z}_{k_{j}}, \lambda_{k_{j}}\right)=h_{\kappa_{k_{j}}}\left(\frac{\widetilde{Z}_{k_{j}}+A_{k_{j}}\left(\lambda_{k_{j}}\right)}{1-A_{k_{j}}\left(\lambda_{k_{j}}\right) \widetilde{Z}_{k_{j}}}, \lambda_{k_{j}}\right),
$$

Here

$$
A_{k_{j}}\left(\lambda_{k_{j}}\right)= \begin{cases}Z_{k_{j}}\left(\alpha_{j}\right) & \text { for } \lambda_{k_{j}} \in\left\langle 0, \alpha_{j}\right), \\ Z_{k_{j}}\left(\lambda_{k_{j}}\right) & \text { for } \lambda_{k_{j}} \in\left\langle\alpha_{j}, \beta_{j}\right\rangle, \\ Z_{k_{j}}\left(\beta_{j}\right) & \text { for } \lambda_{k_{j}} \in\left(\beta_{j}, 2 \pi\right\rangle .\end{cases}
$$

REMARK 5. Let $0<R<1$ and let

$$
\mathbb{S}_{R}^{2}=\left\{\left(z_{1}, z_{2}\right): z_{1}=g_{1}(\zeta), z_{2}=g_{2}(\zeta),|\zeta|<R\right\} \text {. }
$$

Then for every $\left(z_{1}, z_{2}\right) \in \mathbb{S}_{R}^{2}$ and for every $f\left(z_{1}, z_{2}\right) \in \mathscr{F}_{\mathfrak{B}}\left(\mathbb{S}_{0}^{2}, P\right)$ the inequality

$$
\left(e^{-\varepsilon} l\left(\frac{1-r_{0}}{1+r_{0}}\right)^{2 J P Q}\right)^{(1+R) /(1-R)} \leqq\left|f\left(z_{1}, z_{2}\right)\right| \leqq\left(e^{\varepsilon} L\left(\frac{1+r_{0}}{1-r_{0}}\right)^{2 J P Q}\right)^{(1+R) /(1-R)}
$$

holds; here $r_{0}$ depends only upon $\mathfrak{B}, \mathbb{S}_{0}^{2}$ and $\varepsilon$.

Let $\left\{\mathbb{S}^{2}\right\}_{\mathrm{r}_{0}}$ be the set of all segments $\mathbb{S}^{2}$ of analytic surfaces $\mathbb{S}_{0}^{2}$ for which the conditions $1^{\circ}-5^{\circ}$ are fulfilled and for which the set of the corresponding numbers $r_{0}$ has an upper bound smaller than $\mathfrak{x}_{0}<1$. We set

$$
\mathscr{B S}_{R}=\underset{\mathscr{S}^{2} \in\left\lfloor\left(\mathscr{S}^{2}\right\}_{\mathfrak{x}_{0}}\right.}{\mathscr{S}_{R}^{2}}
$$

For every $\left(z_{1}, z_{2}\right) \in \mathbb{S}_{R}$ the inequality

$\left(^{* * *}\right)\left(e^{-\varepsilon} l\left(\frac{1-r_{0}}{1+r_{0}}\right)^{2 J P Q}\right)^{(1+R) /(1-R)} \leqq\left|f\left(z_{1}, z_{2}\right)\right| \leqq\left(e^{\varepsilon} L\left(\frac{1+r_{0}}{1-r_{0}}\right)^{2 J P Q}\right)^{(1+R) /(1-R)}$

holds. Corresponding to $\left\{\&^{2}\right\}_{\mathfrak{x}_{0}}$ we define a sequence of sets $\left\{\mathfrak{A}_{n}\right\}$ by induction as follows:

1. $\mathfrak{\Re}_{1}=\mathbb{S}_{R}$. 
2. $\mathfrak{A}_{n+1}$ is the set of all points $\left(z_{1}, z_{2}\right) \in \mathfrak{B} \backslash\left(\overline{\mathfrak{A}}_{1} \cup \cdots \cup \overline{\mathfrak{A}}_{n}\right)$ which belong to at least one of the analytic surfaces $\mathbb{S}_{n}^{2}$ lying in $\mathfrak{B}$ and having its boundary in $\mathfrak{A}_{1} \cup \cdots \cup \mathfrak{A}_{n}$. The sum of all the sets $\mathfrak{A}_{n}$ will be denoted by $\mathfrak{A}_{R}$ and called the associated domain corresponding to the set $\left\{\mathbb{S}^{2}\right\}_{\mathrm{r}_{0}}$ and to the number $R$. We can prove (similarly to [6], p. 33) that the inequality $\left({ }^{* *}\right)$ holds in the full set $\mathfrak{A}_{R}$ and consequently also in its closure $\overline{\mathfrak{A}}_{R}$.

2. The case of a bounded $p(\lambda)$. If we replace the hypotheses $4^{\circ \circ}$ and $5^{\circ \circ}$ by the condition

$$
p_{j}\left(\lambda_{k_{j}}\right) \leqq P \text { for } \lambda_{k_{j}} \in\left\langle\alpha_{j}, \beta_{j}\right\rangle, j=1, \cdots, J,
$$

the function $f$ which satisfies the hypotheses $1^{\circ \circ}-3^{\circ \circ}$ and the condition (2.1) belongs to the family $\mathscr{F}_{\mathfrak{B}}\left(\mathscr{S}_{0}^{2}, P\right)$ and even to the family $\mathscr{F}_{\mathfrak{B}}^{*}\left(\mathscr{S}_{0}^{2}, P\right)^{11}$. For these functions the inequality (*) follows from Theorem $1^{\prime}$. However, repeating the proof of theorem $1^{\prime}$ and using the condition $(2,1)$ yields a better result.

THEOREM 2. For every $\varepsilon>0$ there exists $r_{0}, 0<r_{0}<1$, such that for every point $\left(z_{1}^{0}, z_{2}^{0}\right) \in \mathbb{S}^{2}$ and for every function $f \in \mathscr{F}_{\mathfrak{B}}^{*}\left(\mathbb{S}_{0}^{2}, P\right)$ the inequalities

$$
\left(l\left(\frac{1-r}{1+r}\right)^{2 P} e^{-\varepsilon}\right)^{\left(1+\left|\zeta_{0}\right|\right) /\left(1-\left|\zeta_{0}\right|\right)} \leqq\left|f\left(z_{1}^{0}, z_{2}^{0}\right)\right| \leqq\left(L\left(\frac{1+r}{1-r}\right) e^{\varepsilon}\right)^{\left(1+\left|\zeta_{0}\right|\right) /\left(1-\left|\zeta_{0}\right|\right)}
$$

hold for every $r \geqq r_{0}$ if $f$ satisfies condition (2.1).

The proof of Theorem 2 proceeds in a way analogous to that of Theorem $1^{\prime}$. Let $\eta=\min \left(\eta^{\prime}, \eta^{\prime \prime}\right)$, where $\eta^{\prime}$ has the same meaning as in the proof on p. 8, and $\eta^{\prime \prime}>0$ is chosen in such a way that for $0<x<\eta^{\prime \prime}$

$$
\begin{aligned}
& \hat{\omega}_{1 j}(x)=x \log \frac{2}{A_{i}}-a_{j} x \log x-a_{j} x<\frac{\pi}{2 J P} \varepsilon, \\
& \hat{\omega}_{2 j}(x)=x \log \frac{2}{B_{j}}-b_{j} x \log x-b_{j} x<\frac{\pi}{2 J P} \varepsilon
\end{aligned}
$$

hold. We choose $r_{0}$ in the same way as before. If we assume, instead of hypothesis $5^{\circ}$, that $1-\left|Z_{k_{j}}(\varphi)\right|$ goes to zero no faster than $\left(\varphi-\varphi_{j}\right)^{a_{j}}$ or $\left(\varphi_{j+1}-\varphi\right)^{b_{j}}$, where $0<\alpha_{j}, b_{j}<1 / 2 P$, when $\varphi \rightarrow \varphi_{j}+$ or $\varphi \rightarrow \varphi_{j+1}$, respectively (hypothesis $5^{\circ \prime}$ ), we can obtain a better inequality.

THEOREM 3. For every sufficiently small $\varepsilon>0$ there exists $r_{0}, 0<$ $r_{0}<1$ such that for every point $\left(z_{1}^{0}, z_{2}^{0}\right) \in \$^{2}$ and for every function $f \in \mathscr{F}_{\mathfrak{B}}^{*}\left(\mathbb{S}_{0}^{2}, P\right)$ the inequalities

11 Indeed, the functions $p_{j}\left(\lambda_{k_{j}}(\varphi)\right), \varphi \in\left\langle\varphi_{j}, \varphi_{j+k}\right\rangle$, being bounded, are square-integrable. 


$$
\frac{1-\left|\zeta_{0}\right|}{1+\left|\zeta_{0}\right|}\left(l\left(\frac{1-r}{1+r}\right)^{2 P}-\varepsilon\right) \leqq\left|f\left(z_{1}^{0}, z_{2}^{0}\right)\right| \leqq \frac{1+\left|\zeta_{0}\right|}{1-\left|\zeta_{0}\right|}\left(L\left(\frac{1+r}{1-r}\right)^{2 P}+\varepsilon\right)^{12}
$$

hold for every $r \geqq r_{0}$, if the function $f$ satisfies the condition (2.1) and if, instead of hypothesis $5^{\circ}$, hypothesis $5^{\circ 1}$ is fulfilled.

Proof. Let $\varepsilon>0$ and $\varepsilon<1 / l$. It follows from hypothesis $5^{\circ \prime}$ that there exist numbers $A_{j}, B_{j}>0$ and $\eta^{\prime}>0$ such that

$$
1-\left|Z_{k_{j}}(\varphi)\right|>A_{j}\left(\varphi-\varphi_{j}\right)^{a j} \text { and } 1-\left|Z_{k_{j}}(\varphi)\right|>B_{j}\left(\varphi_{j+1}-\varphi\right)^{b j}
$$

for $0<\varphi-\varphi_{j}<\eta^{\prime}$ and $0<\varphi_{j+1}-\varphi<\eta^{\prime}$, respectively. Let $\eta^{\prime \prime}>0$ be a number such that, for $0<x<\eta^{\prime \prime}$,

$$
\breve{\omega}_{1 j}(x)=L\left(\frac{2}{A_{j}}\right)^{2 P} \frac{x^{1-2 P a_{j}}}{1-2 P a_{j}}<\frac{\pi}{J} \varepsilon,
$$

and

$$
\breve{\omega}_{2 j}(x)=L\left(\frac{2}{B_{j}}\right)^{2 P} \frac{x^{1-2 P b_{j}}}{1-2 P b_{j}}<\frac{\pi}{J} \varepsilon
$$

hold. We set $\eta=\min \left(\eta^{\prime}, \eta^{\prime \prime}\right)$. There exists $r_{0}, 0<r_{0}<1$, such that

$$
\left|Z_{k_{j}}(\varphi)\right| \leqq r_{0} \text { for } \varphi \in\left(\varphi_{j}+\eta, \varphi_{j+1}-\eta\right), j=1, \cdots, J \text {. }
$$

Applying the Cauchy formula to the function $f\left(g_{1}(\zeta), g_{2}(\zeta)\right)$ which is regular in $|\zeta|<1$ and continuous in $|\zeta| \leqq 1$, dividing the interval of integration and using the inequalities (2.6), (1.4), (2.4), (2.5), and $\left(2.5^{\prime}\right)$, we obtain

$$
\begin{aligned}
\left|f\left(z_{1}^{0}, z_{2}^{0}\right)\right|= & \left|f\left(g_{1}\left(\zeta_{0}\right), g_{2}\left(\zeta_{0}\right)\right)\right|=\left|\frac{1}{2 \pi} \int_{0}^{2 \pi} f\left(g_{1}\left(e^{i \varphi}\right), g_{2}\left(e^{i \varphi}\right)\right) r e \frac{e^{i \varphi}+\zeta_{0}}{e^{i \varphi}-\zeta_{0}} d \varphi\right| \\
\leqq & \frac{1+\left|\zeta_{0}\right|}{1-\left|\zeta_{0}\right|} \sum_{j=1}^{J}\left[\frac{1}{2 \pi} \int_{\varphi_{j+\eta}+\varphi_{j+1}-\eta}^{\varphi_{j}} L\left(\frac{1+r}{1-r}\right)^{2 P} d \varphi\right. \\
& +\frac{1}{2 \pi} \int_{\varphi_{j}+\eta}^{\varphi_{j}+\eta} L\left(\frac{2}{A_{j}\left(\varphi-\varphi_{j}\right)^{a_{j}}}\right)^{2 P} d \varphi \\
& \left.+\frac{1}{2 \pi} \int_{\varphi_{j+1}-\eta}^{\varphi_{j+1}} L\left(\frac{2}{B_{j}\left(\varphi_{j+1}-\varphi\right)^{b_{j}}}\right) d \varphi\right] \\
\leqq & \frac{1+\left|\zeta_{0}\right|}{1-\left|\zeta_{0}\right|}\left[L\left(\frac{1+r}{1-r}\right)^{2 P}+\varepsilon\right] .
\end{aligned}
$$

If we apply the inequality obtained above to the function $1 / f\left(z_{1}, z_{2}\right)$, which also belongs to $\mathscr{F}_{\mathfrak{B}}^{*}\left(\mathbb{S}_{0}^{2}, P\right)$ and for which the condition (2.1) holds, we have the inequality

${ }^{12}$ Here $l=\min \left|f\left(h_{1 k_{j}}\left(0, \lambda_{k_{j}}\right), h_{2 k_{j}}\left(0, \lambda_{k_{j}}\right)\right)\right|, L=\max \left|f\left(h_{1 k_{j}}\left(0, \lambda_{k_{j}}\right), h_{2 k_{j}}\left(0, \lambda_{k_{j}}\right)\right)\right|, l$ may be larger than 1 or $m$ smaller than 1 . 


$$
\left|\frac{1}{f\left(z_{1}, z_{2}\right)}\right| \leqq \frac{1+\left|\zeta_{0}\right|}{1-\left|\zeta_{0}\right|}\left(\frac{1}{l}\left(\frac{1+r}{1-r}\right)^{2 P}+\varepsilon\right)^{13}
$$

for $r \geqq r_{0}$. Hence,

(2.8) $\left|f\left(z_{1}^{0}, z_{2}^{0}\right)\right| \geqq \frac{1-\left|\zeta_{0}\right|}{1+\left|\zeta_{0}\right|} \frac{1}{\frac{1}{l}\left(\frac{1+r}{1-r}\right)^{2 P}+\varepsilon}>\frac{1-\left|\zeta_{0}\right|}{1+\left|\zeta_{0}\right|}\left(l\left(\frac{1-r}{1+r}\right)^{2 P}-\varepsilon\right)$.

From (2.7) and (2.8), (2.3) follows.

REMARK 1. The inequality on the right hand side of (2.3) is obtained in the same way as an inequality obtained by Bergman (see [4] p. 190). Bergman assumes that the function $f$ omits the values 0 and 1 in every lamina and, instead of the inequality (1.5), he applies an inequality, which follows from the Schottky theorem.

The case when $\mathbb{S}_{0}^{2}$ intersects $\mathfrak{b}^{3}$ along only one segment $\mathfrak{e}_{k}^{3}$ so that the line of the intersection $\mathrm{g}^{1}$ lies in $\mathrm{e}_{k r_{0}}^{3}$ is of special interest. This case is considered in remark 2 of $\S 1$. We assume there that the function $f$ belongs to the family $\mathscr{F}_{\mathfrak{B}}^{*}\left(\mathbb{S}_{0}^{2}, P\right)$. However, if we assume in addition that $p\left(\lambda_{k}\right) \leqq P$ (this means that $f\left(h_{1 k}\left(Z_{k}, \lambda_{k}\right), h_{2 k}\left(Z_{k}, \lambda_{k}\right)\right)$ is mean multivalent of at most order $P$ in every lamina $\Im_{k}^{2}\left(\lambda_{k}\right)$ for which $\Im_{k}^{2}\left(\lambda_{k}\right) \cap g^{1} \neq 0$ ) we obtain a better result, using, instead of the Poisson formula, the minimum and maximum principles (see [6], p. 31). This method yields the following theorem:

THEOREM 4. If $\mathrm{g}^{1} \subset \mathrm{e}_{k r_{0}}^{3}, f \in \mathscr{F}_{\mathfrak{B}}^{*}\left(\mathbb{S}_{0}^{2}, P\right)$ and the additional condition $p\left(\lambda_{k}\right) \leqq P$ is satisfied on every lamina $\mathfrak{\Im}_{k}^{2}\left(\lambda_{k}\right)$ which is intersected by $\mathrm{g}^{1}$, then for every $\left(z_{1}^{0}, z_{2}^{0}\right) \in \$^{2}$ and for every $r \geqq r_{0}$ the inequality

$$
l\left(\frac{1-r}{1+r}\right)^{2 P} \leqq\left|f\left(z_{1}^{0}, z_{2}^{0}\right)\right| \leqq L\left(\frac{1+r}{1-r}\right)^{2 P}
$$

holds. Here,

$$
\begin{aligned}
l & =\min _{\lambda_{k} \in s_{k}}\left|f\left(h_{1 k}\left(0, \lambda_{k}\right), h_{2 k}\left(0, \lambda_{k}\right)\right)\right| \\
L & =\max _{\lambda_{k} \in s_{k}}\left|f\left(h_{1 k}\left(0, \lambda_{k}\right), h_{2 k}\left(0, \lambda_{k}\right)\right)\right|
\end{aligned}
$$

$s_{k}$ designates the set of $\lambda_{k}$ for which $\mathfrak{\Im}_{k}^{2}\left(\lambda_{k}\right) \cap \mathfrak{g}^{1} \neq 0$.

REMARK 1. Bergman [2], [3], [4] obtained an upper bound for $|f|$ on an analytic surface, which intersects $\mathfrak{b}^{3}$ along a line lying in $\mathfrak{e}_{k r_{0}}^{3}$, under the assumption that $f$ is a univalent function in every lamina $\Im_{k}^{2}\left(\lambda_{k}\right)$.

$$
18 \max _{\alpha_{j} \leqq \lambda_{k_{j}} \leqq \beta_{j}}\left|\frac{1}{f\left(h_{1 k_{j}}\left(0, \lambda_{k_{j}}\right), h_{2 k_{j}}\left(0, \lambda_{k_{j}}\right)\right)}\right|=\frac{1}{\min _{\alpha_{j} \leqq \lambda_{k_{j}} \leqq \beta_{j}}\left|f\left(h_{1 k_{j}}\left(0, \lambda_{k_{j}}\right), h_{2 k_{j}}\left(0, \lambda_{k_{j}}\right)\right)\right|}=\frac{1}{l} .
$$


The bound is expressed in terms of the maximum of $|f|$ and of the maximum of the absolute value of the derivate of $f\left(h_{1 k}\left(Z_{k}, \lambda_{k}\right), h_{2 k}\left(Z_{k}, \lambda_{k}\right)\right)$ with respect $Z_{k}$ on a one-dimensional manifold lying on $\mathfrak{b}^{3}$.

3. Example. Let $\Phi$ be a univalent function in $|t|<1$, continuous in $|t| \leqq 1,|\Phi(t)|<1$ for $|t| \leqq 1$ and $t \neq \exp \left(i \lambda_{1}^{0}\right),\left|\Phi\left[\exp \left(i \lambda_{1}^{0}\right)\right]\right|=1$. In addition we assume that

$$
\int_{0}^{2 \pi} \frac{d \lambda_{1}}{\left(1-\left|\Phi\left(e^{i \lambda_{1}}\right)\right|\right)^{4}}
$$

exists. Let

$$
\mathfrak{B}=\left\{\left(z_{1}, z_{2}\right): z_{1}=Z, z_{2}=\Phi(t),|Z|<1,|t|<1\right\} .
$$

$\mathfrak{B}$ is a domain which is obtained from the bicylinder $|Z|<1,|t|<1$ by pseudo-conformal mapping $z_{1}=Z, z_{2}=\Phi(t)$. Its three-dimensional boundary $\mathfrak{b}^{3}$ consists of two segments, say $\mathfrak{e}_{1}^{3}$ and $\mathfrak{e}_{2}^{3}$, of analytic hypersurfaces:

$$
\begin{aligned}
& \mathrm{e}_{1}^{3}=\left\{\left(z_{1}, z_{2}\right): z_{1}=Z, z_{2}=\Phi\left(e^{i \lambda_{1}}\right),|Z| \leqq 1,0 \leqq \lambda_{1} \leqq 2 \pi\right\} \\
& \mathrm{e}_{2}^{3}=\left\{\left(z_{1}, z_{2}\right): z_{1}=e^{i \lambda_{2}}, z_{2}=\Phi(t),|t| \leqq 1,0 \leqq \lambda_{2} \leqq 2 \pi\right\} .
\end{aligned}
$$

$\mathfrak{B}$ is obviously an analytic polyhedron. The Bergman-ŠSilov boundary of $\mathfrak{B}$ is a two-dimensional manifold

$$
\mathfrak{F}^{2}=\left\{\left(z_{1}, z_{2}\right): z_{1}=e^{i \lambda_{1}}, z_{2}=\Phi\left(e^{i \lambda_{2}}\right), 0 \leqq \lambda_{1} \leqq 2 \pi, 0 \leqq \lambda_{2} \leqq 2 \pi\right\} .
$$

Let $\mathbb{S}_{0}^{2}$ be a plane

$$
z_{1}=r_{0} e^{i \theta_{0}}, 0<r_{0}<1, \quad \theta_{0} \text { real number . }
$$

The common part $\overline{\mathscr{S}}^{2}=\mathbb{S}_{0}^{2} \cap \overline{\mathfrak{B}}$ can be represented in the form

$$
\bar{\mho}^{2}=\left\{\left(z_{1}, z_{2}\right): z_{1}=r_{0} e^{i \theta_{0}}, z_{2}=\Phi(\zeta),|\zeta| \leqq 1\right\} \text {. }
$$

The intersection $\mathfrak{g}^{1}=\mathbb{S}_{0}^{2} \cap \mathfrak{b}^{3}$ has the parametric representation

$$
\mathrm{g}^{1}=\left\{\left(z_{1}, z_{2}\right): z_{1}=r_{0} e^{i \theta_{0}}, z_{2}=\Phi\left(e^{i \varphi}\right), 0 \leqq \varphi \leqq 2 \pi\right\} .
$$

Here, $\varphi=\lambda_{1}$ and $(d \varphi) /\left(d \lambda_{1}\right)=1$. $\quad\left(\$_{0}^{2}\right.$ intersects the segment $\mathrm{e}_{1}^{3}$ only, and the line of the intersection $\mathfrak{g}^{1}$ lies in $\mathfrak{e}_{1 r_{0}}^{3}$. We consider the function

$$
f\left(z_{1}, z_{2}\right)=\exp \left(\frac{1}{\left(1-z_{1} z_{2}\right)^{2}}-1\right) .
$$

It is holomorphic in $\mathfrak{B}$; its singularities lie on the line

$$
\mathfrak{S}^{1}=\left\{\left(z_{1}, z_{2}\right): z_{1}=e^{i \psi}, z_{2}=\Phi\left[\exp \left(i \lambda_{1}^{0}\right)\right], 0 \leqq \psi \leqq 2 \pi\right\},
$$

which belongs to $\mathfrak{F}^{2} . f\left(z_{1}, z_{2}\right)$ is different from zero and holomorphic in the segment $\overline{\mathbb{S}}^{2}\left(\overline{(S)}^{2}\right.$ has no common points with $\left.\mathfrak{F}^{2}\right)$. Now, we shall prove 
that on every lamina

$$
\Im_{1}^{2}\left(\lambda_{1}\right)=\left\{\left(z_{1}, z_{2}\right): z_{1}=Z, z_{2}=\Phi\left(e^{i \lambda_{1}}\right),|Z| \leqq 1\right\},
$$

except on lamina $\Im_{1}^{2}\left(\lambda_{1}^{0}\right)$, the function (3.2) is mean multivalent of order

$$
p\left(\lambda_{1}\right)=\frac{1}{\pi}\left(2+\frac{1}{\left(1-\left|\Phi\left(e^{i \lambda_{1}}\right)\right|\right)^{2}}\right)+1
$$

in the sense of Biernacki.

Let $a$ be an arbitrary complex number such that

$$
|a| \leqq e^{-2} \text { or }|a| \geqq 1 \text {. }
$$

We want to estimate the number of $a$-points of function (2.3) in lamina (3.3). This number is equal to the number of $a$-points of the function

$$
\exp \left(\frac{1}{\left(1-Z \Phi\left(e^{j \lambda_{1}}\right)\right)^{2}}-1\right)
$$

in the circle $|Z|<1$. We must estimate the number of roots of the equation

$$
\exp \left(\frac{1}{\left(1-Z \Phi\left(e^{i \lambda_{1}}\right)\right)^{2}}-1\right)=a
$$

which lie in $|Z|<1$. From (3.6) we have

$$
Z=\frac{1}{\Phi\left(e^{i \lambda_{1}}\right)}\left(1-\frac{1}{\sqrt{1+\log a}}\right) \text {. }
$$

As $|Z|<1$,

$$
\left|1-\frac{1}{\sqrt{1+\log a}}\right|<\left|\Phi\left(e^{i \lambda_{1}}\right)\right| .
$$

Hence, by hypothesis (3.4)

$$
\frac{1}{\sqrt{|1+\log a|}} \geqq 1-\left|\Phi\left(e^{i \lambda_{1}}\right)\right|
$$

and

$$
|1+\log a| \leqq \frac{1}{\left(1-\left|\Phi\left(e^{i \lambda_{1}}\right)\right|\right)^{2}} .
$$

From (3.7) it follows that

$$
|\arg a| \leqq \frac{1}{\left(1-\left|\Phi\left(e^{i \lambda_{1}}\right)\right|\right)^{2}} .
$$

If we set $\arg a=\operatorname{Arg} a+2 k \pi, k=0, \pm 1, \pm 2, \cdots$, where $|\operatorname{Arg} a| \leqq \pi$, then 


$$
\begin{aligned}
2|k| \pi-|\operatorname{Arg} a| & \leqq \frac{1}{\left(1-\left|\Phi\left(e^{i \lambda_{1}}\right)\right|\right)^{2}} \\
(2|k|-1) \pi & \leqq \frac{1}{\left(1-\left|\Phi\left(e^{i \lambda_{1}}\right)\right|\right)^{2}}
\end{aligned}
$$

and finally

$$
|k| \leqq \frac{1}{\pi}\left(1+\frac{1}{2} \frac{1}{\left(1-\left|\Phi\left(e^{i \lambda_{1}}\right)\right|\right)^{2}}\right) .
$$

The number $n\left(a, \lambda_{1}\right)$ of $a$-points of (3.2) in lamina (3.3) cannot exceed $2|k|+1$; this means that

$$
p\left(|a|, \lambda_{1}\right)=\frac{1}{2 \pi} \int_{0}^{2 \pi} n\left(a, \lambda_{1}\right) d \arg a \leqq \frac{1}{\pi}\left(2+\frac{1}{\left(1-\left|\Phi\left(e^{i \lambda_{1}}\right)\right|\right)^{2}}\right)+1
$$

for $|a| \leqq e^{-2}$ or $|a| \geqq 1$. For numbers $a$ such that $e^{-2} \leqq|a| \leqq 1$, the corresponding number $p\left(|a|, \lambda_{1}\right)$ is $\leqq 1$. Hence,

$$
p\left(\lambda_{1}\right)=\sup _{|a|} p\left(|a|, \lambda_{1}\right) \leqq \frac{1}{\pi}\left(2+\frac{1}{\left(1-\left|\Phi\left(e^{i \lambda_{1}}\right)\right|\right)^{2}}\right)+1 .
$$

The function $p\left(\lambda_{1}\right)$ becomes infinite as $\lambda_{1} \rightarrow \lambda_{1}^{0}$, but $\int_{0}^{2 \pi} p^{2}\left(\lambda_{1}\right) d \lambda_{1}$ exists, as a consequence of (3.1), and

$$
\begin{aligned}
& \frac{1}{2 \pi} \int_{0}^{2 \pi} p^{2}\left(\lambda_{1}\right) d \lambda_{1} \leqq \frac{2}{\pi^{3}}+\frac{2}{\pi^{2}}+\frac{1}{2 \pi} \\
& \quad+\left(\frac{2}{\pi^{3}}+\frac{1}{\pi^{2}}\right) \int_{0}^{2 \pi} \frac{d \lambda_{1}}{\left(1+\left|\Phi\left(e^{i \lambda_{1}}\right)\right|\right)^{2}}+\frac{1}{2 \pi^{3}} \int_{0}^{2 \pi} \frac{d \lambda_{1}}{\left(1-\left|\Phi\left(e^{i \lambda_{1}}\right)\right|\right)^{4}}
\end{aligned}
$$

The function (3.2) belongs to the family $\mathfrak{F}_{\mathfrak{B}}\left(\mathbb{S}_{0}^{2}, P\right)$, where $\mathfrak{B}$ and $\mathbb{S}_{0}^{2}$ are the domains and the analytic surface described above. $P$ equals a square root of the right-hand side of (3.8). Here, $Q=1, J=1$,

$$
\begin{gathered}
l=\min \left(1, \min _{0 \leqq \lambda_{1} \leqq 2 \pi} \mid f\left(0, \Phi\left(e^{i \lambda_{1}}\right) \mid\right)=1\right. \\
L=\max \left(1, \max _{0 \leqq \lambda_{1} \leqq 2 \pi} \mid f\left(0, \Phi\left(e^{i \lambda_{1}}\right) \mid\right)=1 .\right.
\end{gathered}
$$

Applying Theorem 1 and remark 1 of $\S 1$, we can say: for every $\left(z_{1}^{0}, z_{2}^{0}\right)=\left(r_{0} e^{i \theta_{0}}, \Phi\left(\zeta_{0}\right)\right),\left|\zeta_{0}\right|<1$, and for every $r \geqq r_{0}$ the inequalities

$$
\begin{aligned}
\left(\frac{1-r}{1+r}\right)^{2 p\left(1+\left|\delta_{0}\right|\right) /\left(1-\left|\delta_{0}\right|\right)} & \leqq\left|\exp \left(\frac{1}{\left(1-r_{0} e^{i \jmath} \Phi\left(\zeta_{0}\right)\right)^{2}}-1\right)\right| \\
& \leqq\left(\frac{1+r}{1-r}\right)^{2 p\left(1+\left|\zeta_{0}\right|\right) /\left(1-\left|\zeta_{0}\right|\right)}
\end{aligned}
$$

hold. The inequality on the right-hand side of (3.9) gives a better 
estimate for $r_{0}$ and $\left|\zeta_{0}\right|$ sufficiently near to 1 , then the inequality

$$
\left|\exp \left(\frac{1}{\left(1-r_{0} e^{i \theta_{0}} \Phi\left(\zeta_{0}\right)\right)^{2}}-1\right)\right| \leqq \exp \left(\frac{1}{\left(1-r\left|\zeta_{0}\right|\right)^{2}}-1\right),{ }^{14}
$$

which we may obtain directly.

\section{BIBLIOGRAPHY}

1. S. Bergman, Über eine in gewissen Bereichen mit Maximumfläche gültige Integraldarstellung der Funktionen zweier komplexer Variabler, I, II, Math. Z. 39 (1934), 76-94; 605-608.

2. - Über eine Abschätzung von meromorphen Funktionen zweier komplexer Veränderlicher in Bereichen mit ausgezeichneter Randfläche, Trav. Inst. Math. Tbilissi 1 (1937), 187-204.

3. - Über das Varhalten der Funktionen von zwei komplexen Veränderlichen in Gebieten min einer ausgezeichneten Randfläche, Compositio Mathematica 14 (1938), 107-123. 4. - Bounds for analytic functions in domains with a distinguished boundary surface, Math. Z., 63 (1955), 173-194.

5. M. Biernacki, Sur les fonctions multivalentes d'ordre p, C. R. Acad. Sci., Paris 204 (1936), 449-451.

6. Z. Charzyński, Bounds for analytic functions of two complex variables, Math. Z., 75 (1961), 29-35.

7. W. K. Hayman, Multivalent functions, Cambridge University Press, 1958.

8. D. C. Spencer, On finitely mean valent functions, II. Trans. Amer. Math. Soc., 48 (1940), 418-435.

9. — On finitely mean valent functions, Proc, London Math. Soc., (2), 47 (1941), 201-211.

STANFORD UNIVERSITY

UNIVERSITY OF LODZ

${ }^{14}\left|\Phi\left(\zeta_{0}\right)\right| \leqq\left|\zeta_{0}\right|$ by Schwarz' lemma. 



\section{PACIFIC JOURNAL OF MATHEMATICS}

\section{EDITORS}

\author{
Ralph S. Phillips \\ Stanford University \\ Stanford, California \\ M. G. Arsove \\ University of Washington \\ Seattle 5 , Washington
}

\author{
A. L. Whiteman \\ University of Southern California \\ Los Angeles 7, California \\ Lowell J. Paige \\ University of California \\ Los Angeles 24, California
}
E. F. BECKENBACH
D. DERRY
ASSOCIATE EDITORS
T. M. CHERRY
M. OHTSUKA
H. L. ROYDEN
E. G. STRAUS
E. SPANIER
F. WOLF

\section{SUPPORTING INSTITUTIONS}

\author{
UNIVERSITY OF BRITISH COLUMBIA \\ CALIFORNIA INSTITUTE OF TECHNOLOGY \\ UNIVERSITY OF CALIFORNIA \\ MONTANA STATE UNIVERSITY \\ UNIVERSITY OF NEVADA \\ NEW MEXICO STATE UNIVERSITY \\ OREGON STATE UNIVERSITY \\ UNIVERSITY OF OREGON \\ OSAKA UNIVERSITY \\ UNIVERSITY OF SOUTHERN CALIFORNIA
}

\author{
STANFORD UNIVERSITY \\ UNIVERSITY OF TOKYO \\ UNIVERSITY OF UTAH \\ WASHINGTON STATE UNIVERSITY \\ UNIVERSITY OF WASHINGTON \\ AMERICAN MATHEMATICAL SOCIETY \\ CALIFORNIA RESEARCH CORPORATION \\ SPACE TECHNOLOGY LABORATORIES \\ NAVAL ORDNANCE TEST STATION
}

Mathematical papers intended for publication in the Pacific Journal of Mathematıcs should be typewritten (double spaced), and the author should keep a complete copy. Manuscripts may be sent to any one of the four editors. All other communications to the editors should be addressed to the managing editor, L. J. Paige at the University of California, Los Angeles 24, California.

50 reprints per author of each article are furnished free of charge; additional copies may be obtained at cost in multiples of 50 .

The Pacific Journal of Mathematics is published quarterly, in March, June, September, and December. Effective with Volume 13 the price per volume (4 numbers) is $\$ 18.00$; single issues, $\$ 5.00$. Special price for current issues to individual faculty members of supporting institutions and to individual members of the American Mathematical Society: $\$ 8.00$ per volume; single issues $\$ 2.50$. Back numbers are available.

Subscriptions, orders for back numbers, and changes of address should be sent to Pacific Journal of Mathematics, 103 Highland Boulevard, Berkeley 8, California.

Printed at Kokusai Bunken Insatsusha (International Academic Printing Co., Ltd.), No. 6, 2-chome, Fujimi-cho, Chiyoda-ku, Tokyo, Japan.

PUBLISHED BY PACIFIC JOURNAL OF MATHEMATICS, A NON-PROFIT CORPORATION

The Supporting Institutions listed above contribute to the cost of publication of this Journal, but they are not owners or publishers and have no responsibility for its content or policies. 


\section{Pacific Journal of Mathematics}

\section{Vol. 12 , No. 4 \\ April, 1962}

Tsuyoshi Andô, On fundamental properties of a Banach space with a cone ..... . 1163

Sterling K. Berberian, A note on hyponormal operators ................ 1171

Errett Albert Bishop, Analytic functions with values in a Frechet space . . . . . . . 1177

(Sherman) Elwood Bohn, Equicontinuity of solutions of a quasi-linear equation ............................................ 1193

Andrew Michael Bruckner and E. Ostrow, Some function classes related to the class of convex functions . . . . . . . . . . . . . . . . . . . . . . . . 1203

J. H. Curtiss, Limits and bounds for divided differences on a Jordan curve in the complex domain . . ................................. 1217

P. H. Doyle, III and John Gilbert Hocking, Dimensional invertibility . . . . . . . . 1235

David G. Feingold and Richard Steven Varga, Block diagonally dominant matrices and generalizations of the Gerschgorin circle theorem ................. 1241

Leonard Dubois Fountain and Lloyd Kenneth Jackson, A generalized solution of the boundary value problem for $y^{\prime \prime}=f\left(x, y, y^{\prime}\right) \ldots \ldots \ldots \ldots \ldots \ldots \ldots \ldots \ldots$

Robert William Gilmer, Jr., Rings in which semi-primary ideals are primary. . . . . 1273

Ruth Goodman, K-polar polynomials .......................... 1277

Israel Halperin and Maria Wonenburger, On the additivity of lattice completeness ........................................... 1289

Robert Winship Heath, Arc-wise connectedness in semi-metric spaces . . . . . . . . 1301

Isidore Heller and Alan Jerome Hoffman, On unimodular matrices . . . . . . . . . . . 1321

Robert G. Heyneman, Duality in general ergodic theory . . . . . . . . . . . . . . . 1329

Charles Ray Hobby, Abelian subgroups of p-groups . . . . . . . . . . . . . . . 1343

Kenneth Myron Hoffman and Hugo Rossi, The minimum boundary for an analytic

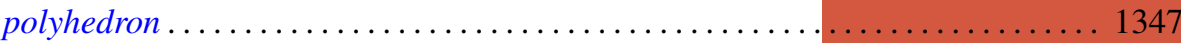

Adam Koranyi, The Bergman kernel function for tubes over convex cones ........ 1355

Pesi Rustom Masani and Jack Max Robertson, The time-domain analysis of a continuous parameter weakly stationary stochastic proces.

William Schumacher Massey, Non-existence of almost-complex structures on

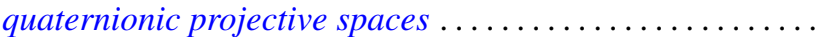

Deane Montgomery and Chung-Tao Yang, A theorem on the action of $\mathrm{SO}(3) \ldots . .1385$

Ronald John Nunke, A note on Abelian group extensions . . . . . . . . . . . . . 1401

Carl Mark Pearcy, A complete set of unitary invariants for operators generating finite $W^{*}$-algebras of type $I$

Edward C. Posner, Integral closure of rings of solutions of linear differential equations.

Duane Sather, Asymptotics. III. Stationary phase for two parameters with an application to Bessel functions.

J. Śladkowska, Bounds of analytic functions of two complex variables in domains

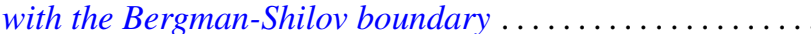

Joseph Gail Stampfli, Hyponormal operators .

George Gustave Weill, Some extremal properties of linear combinations of kernels

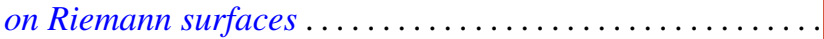

